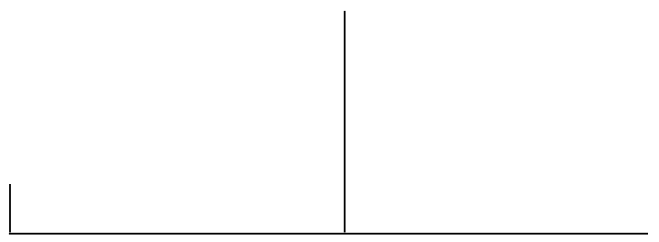

Rev. Latinoam. Psicopat. Fund., São Paulo, v. 15, n. 1, p. 14-26, março 2012

\title{
"Dilthey: compreensão e explicação" e possíveis implicações para o método clínico
}

Sérgio de Gouvêa Franco

NOtA EXPLICATIVA

No dia 20 de outubro de 2011, o Prof. Dr. Sérgio de Gouvêa Franco atendeu gentilmente meu convite e ofereceu aula magistral sobre "Compreensão e explicação em Wilhelm Dilthey", no âmbito do curso sobre "O método clínico" ministrado, durante o segundo semestre desse ano, no Programa de Estudos Pós-Graduados em Psicologia Clínica da Pontifícia Universidade Católica de São Paulo, Brasil. oferta.

Dada a excelente qualidade da aula, propus publicá-la e ele aceitou tal

Prof. Dr. Manoel Tosta Berlinck

Editor Responsável

Revista Latinoamericana de Psicopatologia Fundamental

\section{Introdução geral a Dilthey}

Ainda que seja uma ousadia dar uma aula sobre Dilthey, talvez este momento seja uma forma de ir pagando uma dívida a um pensador importante que é imerecidamente desconhecido no Brasil. Sua filosofia está apresentada em inglês em uma coleção de seis volumes, da qual tomo apenas o volume IV intitulado "Hermenêutica e o Estudo da História" para discutir o tema da "compreensão e explicação" e possíveis 
implicações para o método clínico, tão importante para nossa psicopatologia fundamental. Os demais volumes da coletânea não foram examinados. Tampouco tenho condições de lê-lo no original alemão. Em espanhol a obra de Dilthey é editada em oito volumes, a coletânea é dirigida por ninguém menos que o grande Ortega y Gasset. Uma versão mais completa que a edição inglesa, o que mostra a dificuldade da penetração de Dilthey não apenas no Brasil, mas também no mundo anglo-saxão. As obras completas em alemão têm 14 volumes. Logo se vê o fôlego de seu trabalho e se toma consciência de que muita coisa ficou fora da versão inglesa, e mesmo espanhola. Sua obra é um grande apanhado da história e teoria das ciências humanas e um grande esforço filosófico para oferecer compreensão sobre o sentido da história e da vida humana.

O interesse em Dilthey, na Europa e Estados Unidos, cresceu recentemente como efeito dos estudos sobre Husserl, Heidegger, Sartre e das disciplinas hermenêutica, estruturalismo e teoria crítica. Foi ficando claro que todos estes autores e estas disciplinas têm raízes, até então não plenamente reconhecidas, no pensador alemão do século XIX e início do XX. Poderíamos fazer uma frase de efeito para descrever o pensamento de Dilthey: “... não dá para pensar criticamente as ciências humanas sem recorrer a ele". Dilthey é um titã que resiste à completa absorção dos estudos humanos em uma abordagem unificada pelos princípios do positivismo. Ele diz não a isto, sustenta a especificidade dos estudos científicos e filosóficos do humano, destacando que as humanas compreendem (verstehen) e as ciências naturais explicam (erklären). Embora esta divisão tenha sido frequentemente levada muito além do que Dilthey pretendia, longe demais, enfraquecendo sua posição.

De qualquer forma, seu pensamento sustenta uma posição rica que fenomenólogos contemporâneos desposam: a relação entre humanas e exatas tem continuidade e descontinuidade. Não convém separá-las demais porque ambas são ciência, não convêm aproximá-las demais porque têm objeto de estudo muito diverso. Estes fenomenólogos de inspiração em Dilthey vão promover um giro e dizer que não se trata apenas de reconhecer as influências das ciências naturais nas humanas. $\mathrm{O}$ inverso também é verdade. Humanas e naturais interpretam o seu objeto de estudo. É impossível fugir disto, sempre há uma circulação entre o sujeito e o objeto do conhecimento. O trabalho é mostrar como as humanas fazem isto e como o fazem as naturais/exatas. Dilthey não pretende que não haja explicação nas ciências humanas. Existe, ele afirma. Ele apenas delimita o seu alcance. Seria trair seu pensamento, igualar compreensão a simples empatia. É muito mais do que isto. Neste sentido, Dilthey não opõe nem iguala ciências humanas e ciências naturais. As diferenças são, sobretudo, de grau e de intensidade, menos que de radical diferença. 


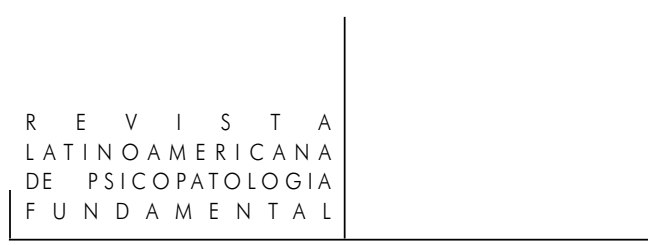

\section{Introdução ao IV volume: Hermenêutica e o Estudo da História}

Dilthey abre um de seus escritos de 1860 com uma frase de força: “... a ciência da hermenêutica realmente começa com o protestantismo, ainda que a arte da exegese e a reflexão sobre ela, certamente, sejam muito mais antigas". Ele conhece os instrumentos sofisticados da interpretação protestante, forjados no esforço de elucidação do texto bíblico, em particular, conhece Schleiermacher. Seu pensamento filosófico é tributário destes estudos, elaborando a natureza do que seja compreensão. Autores do século XX, como Heidegger, são tributários, por sua vez, do pensamento dele. É impressionante a erudição de Dilthey, vasculhando autor por autor desde o século XVI, início do protestantismo, até Schleiermacher no início do século XIX.

O protestantismo quer libertar a leitura da Bíblia de uma abordagem dogmática patrocinada por Roma. O famoso bordão de Martinho Lutero, sintônico com o homem moderno, "só as Escrituras", é um ataque ao direito de Roma de fazer a interpretação oficial do texto. O trabalho da Reforma Protestante, mapeado cuidadosamente por Dilthey, é a construção de princípios de interpretação do texto que desmontam uma leitura preconcebida pela Igreja medieval. O texto deve falar o que fala, ofenda ou não uma tradição, ofenda ou não uma doutrina sustentada pela Igreja. A hermenêutica se torna gramatical e histórica. O que a exegese gramatical nos ensina sobre o sentido do texto? O que o contexto histórico onde ele foi produzido nos ensina sobre o seu sentido? Esta hermenêutica destrói a abordagem alegórica sustentada por Roma e que sustentava sua dogmática, com enormes implicações políticas, epistemológicas e hermenêuticas. A Bíblia fica livre para dizer o que quiser sem a domesticação do magistério eclesiástico. O protestantismo quer que o texto seja livremente lido por todos. A filologia é grandemente valorizada.

Quando Dilthey chega a Schleiermacher, ele dá um salto da teologia para a filosofia, ligando todos estes estudos hermenêuticos ao idealismo e ao romantismo alemães. Destaque para Schelling na tradição idealista e Schleiermacher na tradição romântica. É este que empurra Dilthey para o esforço de compreensão do autor do texto. Schleiermacher propõe uma circulação entre os polos objetivo e subjetivo da leitura. Objetivamente, a leitura do texto é construída pelo esforço histórico-gramatical. Subjetivamente, por uma compreensão psicológica do autor. Os polos objetivo e subjetivo entram em circulação, envolvendo o intérprete. É assim que Dilthey amplia sua teoria da compreensão, indo além de uma hermenêutica religiosa e lançando bases para uma teoria das ciências humanas. Hermenêutica passa a ser assunto da filosofia e da história. Dilthey vai inserir seus estudos sobre a noção de compreensão na tradição da filosofia alemã: Winckelmann, Herder, Lessing, além de Goethe, Humboldt e Schlegel. Passa a 


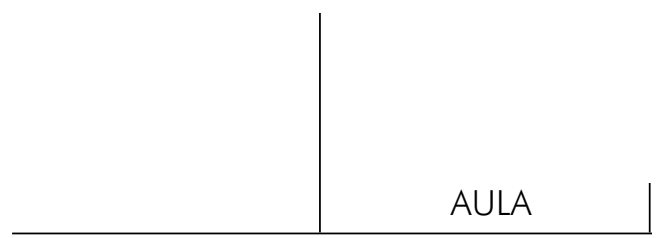

valorizar a intuição da individualidade. É importante, no entanto, destacar que Dilthey se afasta de qualquer apreensão especulativa do outro. Ele busca algo que possa ser empiricamente testado, descritivo e que possa ser psicologicamente sustentado. A compreensão em Dilthey é, assim, sempre um caminho, uma mediação. Não se trata nunca de uma visão, de uma opinião imediata. Deste modo, compreensão não é uma apreensão intuitiva e imediata do outro. Dilthey propõe um entendimento crítico da compreensão que acolhe o lugar da intuição e do sentimento, mas nunca à custa do intelecto e da função crítica.

Vale a pena também dizer da importância que a noção de história passa a ter para Dilthey. Ele sempre mantém uma posição intermediária, foge ao mesmo tempo da especulação e do positivismo. Esta é a posição que Husserl e seus seguidores também sustentam, e vamos arriscar dizer, Freud também. É assim que ele vai sustentar a hermenêutica em uma compreensão histórica do humano. Este é seu projeto epistemológico. Sumarizando, ele começa como um historiador do pensamento protestante e passa a problemas gerais da interpretação do próprio humano que é capturado em sua objetividade e subjetividade, que é visto não positivistamente nem especulativamente, mas capturado em uma compreensão com base na história.

Hermenêutica e sua história

O volume IV da coletânea que estamos estudando está dividido em duas partes. A primeira se intitula "Hermenêutica e sua história". O primeiro ensaio desta parte é um longo estudo sobre Schleiermacher. Mostra como o protestantismo como já dissemos a pouco - afirma que todos têm acesso ao sentido da Bíblia e coloca em xeque a interpretação não literal, alegórica, de Roma, que pretende manter a compreensão de mundo da Igreja medieval. Schleiermacher, quando entra no cenário do pensamento protestante, propõe uma leitura simbólica, não alegórica, do texto bíblico, ou de qualquer texto. Propõe uma circulação entre a leitura gramatical e a leitura psicológica do texto, mostrando a interdependência das duas abordagens. Os estudos gramaticais em Schleiermacher ganharam uma nova dimensão porque ele passa a discussões sobre a natureza da linguagem e como esta desvela o humano. Quando ele fala da dimensão psicológica da interpretação, pensa nos momentos existenciais geradores do texto. A compreensão depende da capacidade de capturar o estado psicológico do outro, que só pode ser feita mediante a linguagem. Schleiermacher propõe o que se chama de um círculo hermenêutico, onde a compreensão só emerge quando há uma circulação entre as partes componentes e o todo, entre os polos objetivo e subjetivo. Assim foi possível reconstruir o estado mental que permitiu a criação do texto a sua frente.

Rev. Latinoam. Psicopat. Fund., São Paulo, v. 15, n. 1, p. 14-26, março 2012 
Dilthey se apropria de vastas porções do pensamento de Schleiermacher, escolhido como o mais interessante da tradição protestante, para entender a fala humana.

No segundo ensaio da primeira parte do livro Sobre compreensão e hermenêutica, Dilthey trabalha a distinção explicação/compreensão. Enquanto nos estudos sobre Schleiermacher, Dilthey destaca a continuidade entre a explicação e compreensão, aqui ele explora a descontinuidade dos conceitos. Uma visão excessivamente explicativa sobre o humano destruiria a condição de liberdade na história. Só a noção de compreensão faz justiça a esta experiência interior e central da ação humana. A explicação se presta a forças físicas, fala dos efeitos, mas não da natureza das agências envolvidas. Muito interessante é sua afirmação sobre "compreender tudo": “... o ser humano que compreendesse tudo, não seria humano". Isto porque compreender é capturar a individualidade, e nossa capacidade de capturar a individualidade é sempre limitada por nossa própria individualidade. A compreensão no pensamento de Dilthey não é uma questão do pensamento abstrato. Ela exige o envolvimento de quem compreende, que participa também com imaginação, para enxergar o universal no particular e o todo na parte. Dilthey propõe que compreender é um trabalho que vai de particular em particular. A primeira leitura não pode produzir a compreensão. A compreensão é mais que compreender os sentidos das palavras do texto. Trata-se de um esforço imaginativo que aproxima o leitor do autor do texto, envolvendo um julgamento do leitor. A reconstrução da vida íntima do autor envolve a gramática, mas vai além para se assentar em uma compreensão histórica de quem é o ser humano.

O último ensaio da primeira parte "O aparecimento da hermenêutica" procura a origem da hermenêutica no pensamento antigo greco-romano. Sua erudição no pensamento grego clássico - Platão e Aristóteles - e na patrística cristã mais uma vez impressiona. Um dos temas principais do ensaio é o da distância entre o leitor, o intérprete, o texto e o seu autor. Hermenêutica é exatamente o trabalho de aproximação entre estes dois mundos. A hermenêutica é uma chave que ajuda a interpretar, a compreender, os produtos objetivos da história humana. Neste sentido, o ensaio tem o projeto de aproximar explicação e compreensão.

\section{Interpretação da história}

A segunda parte de nosso livro é intitulada de "Interpretação da história". Os artigos iniciais são um esforço para marcar a posição de Dilthey em relação aos positivistas franceses e ingleses e também em relação a outros especialistas em história alemães. Por um lado ele ataca a possibilidade de uma leitura da história 
nos moldes das ciências naturais, defendendo uma compreensão antipositivista da história, sem cair no campo especulativo como, por exemplo, em Hegel. O que ele busca são movimentos e leis que emergem da própria história. O positivismo é criticado por não sustentar a distinção metodológica entre as ciências humanas e as ciências naturais. A história não pode ser reduzida a um trabalho estatístico com os dados empíricos. É mais do que isto. No trabalho histórico cabem perguntas mais profundas e mais abrangentes. Além disto, Dilthey possui uma visão da causalidade histórica bem complexa. Não se trata de descobrir nos relatos um contínuo de explicações causais, mas compreender um conjunto de fatores genéticos que constrói o rico tecido histórico. Não há como enfileirar eventos, onde um é a causa do outro. Outro elemento que pode ser destacado destes artigos é sua visão teleológica imanente. Ele recusa uma teleologia filosófica como em $\mathrm{He}$ gel, ou teleologia teológica. Se a história caminha para algum lugar, este caminho é dado por forças que pertencem à própria história, ou seja, são imanentes àquela. O esquema de Comte, por exemplo, com três etapas históricas, é criticado como uma imposição artificial e externa a própria história. Desta rica visão de história emerge uma visão do homem: o homem é sempre histórico, não pode ser pensado à parte dela. O homem, só é possível compreendê-lo se recorrermos ao seu passado.

O quarto artigo desta parte "O século XVIII e o mundo histórico" lida com o Iluminismo. Ele é um crítico do racionalismo e simpatiza com as vertentes românticas já presentes no esclarecimento iluminista. No presente artigo atenua críticas iniciais mais radicais contra o Iluminismo para se distanciar do irracionalismo emergente das obras de Schopenhauer e Nietzsche. Dilthey critica os autores do Iluminismo por não demonstrarem uma compreensão genética da história, mas uma compreensão excessivamente intelectualizada dos motores históricos. Para Dilthey a compreensão adequada é mais orgânica porque intui melhor a complexidade do espírito humano, tomando a experiência vivida como o elemento central. O último e derradeiro ensaio destaca o mesmo, a importância de uma leitura dos movimentos humanos na história. Não se trata de ter uma leitura filosófica da história, mas procurar, filosoficamente, entender a consciência humana que emerge da história.

\section{Biografia e bibliografia de Dilthey}

Wilhelm Dilthey nasceu em 19 de novembro no vilarejo de Biebrich, região da Renânia, na Alemanha, em 1833, dois anos após a morte de Hegel. Fez sua formação básica na sua cidade natal e depois foi estudar teologia na Universida- 
de de Heidelberg. Depois de três semestres, mudou-se para Berlim onde passou a estudar história. Com vistas a atender expectativas paternas, ele fez os exames finais em teologia e pregou seu primeiro sermão em 1856. Começou a vida como professor secundário; após dois anos ensinando teve licença por questões de saúde. Nos anos subsequentes tornou-se pesquisador em Berlim com estudos históricos e filosóficos. Em 1864, passou a professor universitário com um trabalho de entrada sobre a ética de Schleiermacher. Ensinou em Basileia e Berlim. Na Universidade de Berlim ocupou a mesma cadeira de filosofia que Hegel. Casou-se com Catarina com quem teve um filho e duas filhas. Faleceu em 3 de outubro de 1911.

Publicou pouco durante a sua vida, mas após sua morte suas obras sobre história e filosofia foram reunidas em 14 volumes. Em 1883, publicou o primeiro volume de sua Introdução às ciências humanas. Seu projeto original, por muito pretensioso, nunca foi concluído. O segundo volume ficou incompleto e só foi publicado após sua morte. Na Introdução às ciências humanas, ele faz uma história das ciências humanas e trata da ascensão e queda da metafísica. Para ele, a visão das ciências humanas, proposta pelas ciências naturais e pela metafísica, é inaceitável. Busca construir um status mais elevado para os estudos humanos. As ciências humanas precisariam ser abordadas como uma coisa orgânica e vital. O método da explicação das ciências naturais não é capaz disto. A aplicação bem-sucedida do pensamento de Hobbes, David Hume e Spinoza às ciências naturais induziu uma abordagem dos estudos humanos inspirados no método explicativo. Para Dilthey, é seria uma abordagem reducionista que finalmente desvaloriza as ciências humanas, colocando-as em um lugar menor. Dilthey propõe outro fundamento para as ciências humanas: a autorreflexão fundada na experiência da vida. Sem entrar em toda a tecnicalidade filosófica, podemos dizer que o que pensa tem muita similaridade com o que Husserl, Heidegger e vários fenomenólogos do século XX vão mais tarde também pensar.

Outro livro importante é Ideias sobre uma psicologia descritiva e analítica de 1894. Nesse livro procura construir uma psicologia não com uma base naturalista; esta psicologia serve como base e referência para todas as ciências humanas. Nesse livro fica claro que, nas ciências humanas, o que temos é uma compreensão do humano e não uma explicação como nas ciências naturais. Sua abordagem recusa toda visão meramente intelectual do humano que, para ele, é emoção, pensamento e vontade como em Kant. No livro $O$ aparecimento da hermenêutica, de 1900, ele desenvolve a ideia de que só podemos nos dar conta do que somos por nossa produção objetiva.

\section{[Intervalo]}


AULA

\section{Os conceitos "Compreensão e Explicação" na contemporaneidade}

Gostaria de fazer agora uma discussão sobre Dilthey, aproximando-o do mundo contemporâneo. Os debates acerca dos conceitos de compreensão e explicação têm dimensões epistemológicas e filosóficas amplas. Na medida em que a discussão vai se aprofundando vai se dando conta ao mesmo tempo de sua complexidade. Uma primeira questão seria se as ciências, naturais e humanas, constituem um campo único e contínuo ou há uma descontinuidade quando se passa de um para outro tipo de ciência. Explicação, como proposto por Dilthey, está associada ao campo das ciências naturais e compreensão ao campo das ciências humanas. Quando se valoriza a explicação como principal elemento do trabalho científico, a diferenciação entre os dois tipos de ciência se esvai. A noção de compreensão, por outro lado, destaca que não pode haver ciências humanas e sociais sem a valorização da peculiaridade dos estudos humanos. Esta distinção tem a ver com aceitação do fato de que o fenômeno humano não é inteiramente reduzível aos fatos e leis das coisas naturais. Esta é a sustentação que pretende Dilthey.

Embora não haja um radicalismo em Dilthey, uma oposição forte entre compreensão e explicação, promovido por certas leituras apressadas, nos conduziria a um lugar dicotômico. Inspirado aqui e ali, sobretudo em Ricoeur e Gadamer, gostaria de promover uma redução da distância entre os dois conceitos: compreensão e explicação. Proponho, antes que uma oposição radical, uma dialética entre os termos. Assim toda interpretação efetiva teria momentos de explicação e momentos de compreensão. Estaríamos assumindo que entre ciências humanas e naturais há, ao mesmo tempo, continuidade e descontinuidade. Poderia parecer pouco dizer isto, mas trata-se, de certa forma, de sustentar o jogo de posições e diversidades que quer sustentar a psicopatologia fundamental. Não se pode dizer: “... sou pela subjetividade, sou pelas humanas" e desistir do lugar da matemática e da importância das ciências da experimentação. A relação entre natureza e cultura terá que ser mais complexa que isto. $\mathrm{O}$ futuro dos estudos da subjetividade, quer me parecer, tem a ver exatamente com a capacidade de fazer luto desta tensão, algo infantil, das humanas contra as ciências naturais e exatas.

Dilthey é o pensador alemão da teoria da compreensão. Mas é preciso dizer que ele não quer tanto opor uma visão romântica da realidade a uma visão científica como foi concebida por Galileu, Descartes e Newton. O que ele pretendia era dar respeitabilidade científica à compreensão, como a explicação já possuía. Não podemos esquecer que para ele, a compreensão nasce do polo objetivo, dos produtos humanos na história. Não parte de uma introspecção subjetiva ou de uma especulação filosófica. O que Dilthey está dizendo é que toda manifestação objetiva do humano tem um sentido maior que se encontra no campo do espírito. 
Gostaria de recuperar por um minuto a posição de Schleiermacher acerca da interpretação de um texto, tão cara a Dilthey. Schleiermacher se aproxima do domínio explicativo quando valoriza todo o trabalho crítico textual, a tradição histórico gramatical que não levanta sequer uma pergunta sobre as dimensões subjetivas do texto. O texto é visto como uma relação de funções internas. Schleiermacher, no entanto, vai além, ele busca também o que poderíamos chamar de uma comunhão entre a mente do leitor moderno e do autor antigo. Agora, o que falta em Schleiermacher, poderíamos dizer, é uma dialética mais bem estabelecida entre os polos da explicação e da compreensão. Schleiermacher promove uma exclusão da lógica da compreensão quando faz uma explicação e depois faz o contrário. Se é que nos autorizamos a usar termos que não estão plenamente amadurecidos na época de Schleiermacher. Mas uma dinâmica entre os dois polos pode ter sua riqueza. Neste sentido, a explicação pode promover a compreensão. E a compreensão se assenta sobre fundamentos objetivos da realidade. A explicação, em vez de se opor à compreensão, é seu esteio. Não há compreensão intersubjetiva sem a mediação do trabalho objetivo da linguagem. Podemos dizer também que o trabalho explicativo encontra sua culminação na compreensão, para não deixar a explicação estreita demais. Uma crítica que poderia ser levada até a posição de Schleiermacher é que ele pretende uma psicologização desnecessária. Não se pode recuperar totalmente o autor atrás do texto. O que se pode fazer é recuperar uma subjetividade escondida no texto, não plenamente identificável com um autor que se perdeu na história.

Outro lugar interessante para aproximar a discussão compreensão/explicação é a discussão motivo/causa. Em que medida a ação humana é motivada ou causada por estímulos externos? Na direção do que estamos dizendo, podemos pensar que se trata de um contínuo: em um extremo a causalidade e no outro a motivação. Causalidade sem motivação é puro constrangimento, refere-se à violência. Para colocar no campo de Freud, certos motivos inconscientes são de tal intensidade e natureza, pensados pelo próprio Freud em termos econômicos, que podem ser falados como causas da ação humana, não de motivos. Por outro lado certas ações humanas, por exemplo, no campo do lazer, que estão tão sem causa, são pura motivação. No dia a dia da ação humana, parece razoável dizer que tanto motivação como causa comparecem como motor, demandando assim explicação e compreensão. Talvez seja ainda necessário dizer que uma visão da ação humana inteiramente determinada, explicada por causas, é ilusória, como querem os positivistas.

Do ponto de vista epistemológico, temos dois métodos: a explicação e a compreensão. Mais rigorosamente apenas a explicação é um método inteiramente constituído. Compreensão é uma tarefa interpretativa que precede, acompanha e encerra o trabalho da explicação. Podemos dizer que há uma relação complexa e 


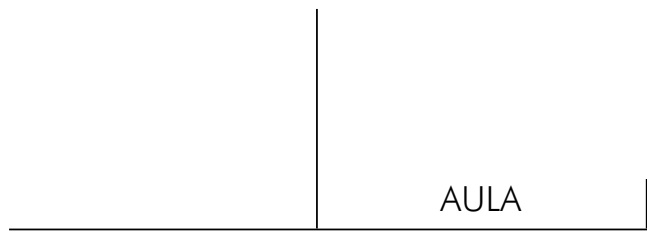

dialética, em grande medida paradoxal, entre as ciências humanas e as naturais. A palavra compreensão tem este poder de trazer à tona também esta dimensão que excede, que ultrapassa, que vai além do que caracteriza o humano. Esta dimensão em grande medida inominável que rege a liberdade humana, que não pode ser explicada. E, caso seja eliminada, retira do humano aquilo que lhe é próprio.

\section{Explicação e compreensão na psicanálise}

Gostaria de mencionar agora a leitura filosófica que Paul Ricoeur faz da obra de Freud. Chamo à cena esta leitura porque o filósofo francês encontra em Freud algo como uma tensão entre explicação e compreensão. Para Ricoeur, Freud fala duas línguas. Em Freud, há questões de sentido: sentido dos sonhos, dos sintomas e da cultura. Há também uma fala sobre forças: catexia, conflito, repressão e contabilidade econômica. Alguém poderia pensar que esta dupla face de Freud é um equívoco, um engano, ou um descuido. Ricoeur sustenta que Freud sabe o que faz; diz que pretender destituir seu discurso deste duplo caráter é diminuir sua potência. O texto de Freud une exatamente força e sentido em uma semântica do desejo humano.

Depois de uma leitura cuidada de Freud, Ricoeur pretende inserir o seu pensamento na tradição do pensamento ocidental. Não se trata de fazer de Freud um filósofo, mas reconhecer implicações filosóficas de sua obra. Implicações que possivelmente Freud não estaria plenamente consciente. A leitura aqui se caracteriza por enxergar na fala psicanalítica uma dualidade de discurso: Freud se referiria ao funcionamento do aparelho psíquico em termos de sentido e em termos de força. O que Ricoeur afirma é que a psicanálise vai se constituir como disciplina científica exatamente recusando optar entre estas duas linguagens. A psicanálise é tanto uma compreensão de sentidos quanto uma energética que explica as forças em jogo na psique humana. Compreensão e explicação juntas.

Esta tese de Ricoeur, na verdade, representa uma solução para uma disputa entre duas leituras concorrentes da obra de Freud. Há quem veja Freud como um naturalista. Sua metodologia de trabalho deveria ser comparada a da biologia ou da física. O homem freudiano, segundo esta corrente, é em essência um complexo pulsional, um produto dos impulsos que vêm do corpo. Nesta visão de viés positivista, o psiquismo seria "infiltrado" e determinado pelo corpo. Assim, a linguagem mecanicista de Freud é que deve ser privilegiada. O homem deve ser compreendido a partir de um jogo de forças cegas.

Os críticos desta visão naturalista de homem hão de dizer que esta concepção deixa de fora exatamente o que há de mais essencial e mais humano no ho- 
mem; reducionista, esta visão não trabalha o sentido da existência humana. O ponto aqui não é só que esteja faltando algo na visão naturalista. De fato, outros tantos leitores de Freud vão dizer que sua obra é uma pesquisa constante do sentido, uma busca de significações ocultas. A própria relação terapêutica na psicanálise só pode ser pensada como uma produção de sentidos. O sentido dos sintomas está oculto aos pacientes, as significações que a sessão produz tratam exatamente de devolver o sentido ao paciente. Esta outra corrente, então, quer privilegiar a decifração de sentido na obra de Freud. E assim fica instaurado o conflito, será Freud um naturalista ou será um intérprete de sentidos? A psicanálise deve ser compreendida como um jogo de forças ou como uma decifração de sentidos?

Penso que não há muita dúvida de que é possível encontrar elementos tanto de uma metodologia de decifração quanto de uma doutrina mecanicista em Freud. Diante destes dois padrões de discurso, as correntes acima mencionadas têm tentado separar um Freud de outro. Quem quisesse fazer uma leitura seletiva de Freud não terá muita dificuldade para sustentar uma ou outra destas visões. Pode-se justificar a seleção dos textos segundo um critério cientificista. Assim é que se procura trazer Freud à condição de ciência positiva, retirando dele qualquer meditação existencial. Por outro lado, é possível tentar extirpar qual elemento energético de Freud, alegando que este material deva ser considerado um ranço positivista herdado do século XIX. A psicanálise se tornaria então um trabalho sobre o sentido e a ocultação do sentido na vida humana.

A dificuldade destas propostas de separar os "dois" Freuds é que esta separação representa uma enorme violência ao texto freudiano. As duas linguagens estão ali, o tempo todo. Nem mesmo se pode dizer que haja uma direção ou um movimento onde uma linguagem vá superando a outra. Há sim momentos mais energéticos e há momentos mais interpretativos. Mas os momentos energéticos são seguidos por momentos interpretativos e vice-versa. $\mathrm{O}$ texto freudiano não recomenda a separação nem a exclusão de uma das linguagens. Pelo contrário, Freud parece se sentir muito à vontade com os seus dois estilos de falar. Parece que para ele não há contradição entre decifração de sentidos e explicação energética.

O que está implicado na tese de Ricoeur é que não foi por uma espécie de inércia filosófica que Freud manteve a fala de força em seu discurso. Nem Freud seria um mau cientista que, por descuido ou falta de rigor, tivesse permitido a introdução de elementos não quantificáveis em seu discurso. Para Ricoeur, Freud sabia o que estava fazendo. Ele não crê que Freud estivesse construindo este enorme arcabouço metapsicológico imerso em uma grande ingenuidade epistemológica. Prefere crer que Freud deliberadamente reuniu duas ordens de discurso diversas: a linguagem da força e a linguagem do sentido. Nestes termos, o pro- 


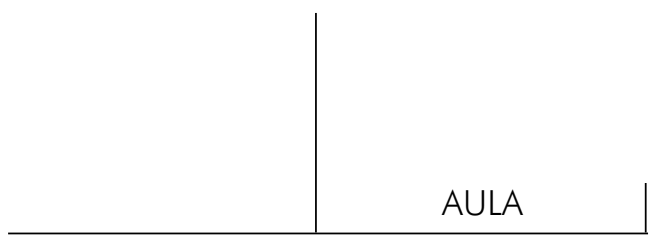

blema não se localiza na escolha de uma linguagem em detrimento da outra. Talvez, sugere Ricoeur, a questão é que faltaram condições a Freud para demonstrar mais claramente a articulação destas duas linguagens.

Se isto estiver certo, é necessário defender a presença das duas linguagens em Freud. É legítimo o esforço para combater a tentativa de extirpar um dos Freuds para ficar com o outro. Ricoeur, ele mesmo, não pretende preencher uma suposta lacuna criada pelo pensamento de Freud. Sugere apenas enxergar, nos dois componentes do pensamento de Freud, uma dialética entre força e sentido. Quando estuda o "Projeto...", ele fala de um estado energético da teoria, sem ou com pouca interpretação de sentido. A antítese poderia ser encontrada em certas passagens de A interpretação dos sonhos, onde a interpretação floresce. Por fim, a síntese, ou o equilíbrio entre força e sentido, seria encontrado nos escritos ditos metapsicológicos. O que pretende Ricoeur é mostrar a irredutibilidade do discurso freudiano à linguagem, quer do sentido quer da força. Crê que finalmente não há conflito entre as duas ordens de linguagem. E aponta o conceito de pulsão em Freud como um lugar privilegiado desta harmonia. No conceito de pulsão freudiano, vê reunido tanto o sentido quanto a força.

Agora, para compreender o que Ricoeur está fazendo é preciso não se ater à psicanálise. $\mathrm{O}$ trabalho que Ricoeur empreende é um passo a mais em um projeto filosófico. A indissolubilidade da explicação causal, por forças de uma compreensão de sentidos, não caracteriza somente a psicanálise, mas toda ciência do homem que aspire explicar efetivamente o comportamento humano. Para Ricoeur isto é claro. Quando ele estuda a história, quando ele analisa um texto ou quando trabalha o inconsciente, sempre pensa o homem como um misto de busca de sentido e constrangimento de forças.

Em seu artigo "Expliquer et comprendre" rejeita a distinção que associa explicação às ciências naturais e associa compreensão às ciências humanas. Para Ricoeur, explicação e compreensão são dois modos irredutíveis de compreender a realidade. Por isso, propõe uma dialética entre os dois termos. Entre as ciências humanas e as ciências naturais não há somente descontinuidade, há também continuidade. É por isso que mesmo em ciências humanas é justo falar-se em jogo de forças. A diferença entre as ciências humanas e as ciências naturais é de grau, não de qualidade. Então é que se compreende que a visão de Ricoeur da psicanálise está baseada em uma hipótese antropológica mais abrangente. Sustenta com este ponto que muitos temas freudianos tocam profundos problemas filosóficos que ainda não foram plenamente explorados. 


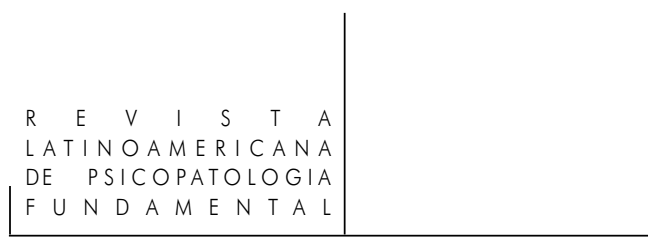

\section{Conclusão}

Para encerrar, quero ainda dizer que estas são nossas contribuições para aproximar Dilthey ao pensamento contemporâneo e ao Método Clínico. Não pretendo fazer mais do que isto. Não quero forçar uma aproximação que ainda não amadurecida. Não há dúvida que as questões hoje colocadas sustentam uma abordagem humana do humano, uma valorização da subjetividade. As discussões valorizam também a individualidade e a singularidade dos indivíduos. Sintônico com o respeito da diversidade, as discussões de hoje reconhecem que na polis falam não apenas os que se amparam em métodos dito das humanas, mas também os que se amparam mais nos métodos ditos das ciências naturais. Completar as implicações para o método clínico do pensamento de Dilthey, no entanto, fica ainda como uma tarefa em aberto, não realizada, à disposição dos que querem trabalhar... Sabemos que é nesta tensão e nesta dialética compreensão/explicação que se vai construindo um discurso, sempre precário, sobre a experiência pática de homens e de mulheres sobre a face do terceiro planeta do sistema solar.

Obrigado.

\section{Sérgio de Gouvêa Franco}

Psicanalista com prática clínica em São Paulo. Doutor pela Universidade Estadual de Campinas - Unicamp (Campinas, SP, Br) e pós-doutor em psicologia clínica pela Pontifícia Universidade Católica de São Paulo - PUC-SP (São Paulo, SP, Br); Pesquisador da Associação Universitária de Pesquisa em Psicopatologia Fundamental; Tem formação em ciências duras e humanidades no Brasil pela Universidade de São Paulo - USP) (São Paulo, SP, Br) e no exterior, no Regent College (Canadá); Professor titular de psicologia da Universidade Paulista - Unip (São Paulo, SP, Br) e do Centro Universitário SENAC (São Paulo, SP, Br); Foi Reitor da Fundação Escola de Comércio Álvares Penteado - Fecap (São Paulo, SP, Br) entre os anos 2006 e 2010; Autor do livro Hermenêutica e psicanálise na obra de Paul Ricoeur e de vários artigos publicados em coletâneas, revistas brasileiras e estrangeiras; Membro do Departamento de Psicanálise do Instituto Sedes Sapientiae.

Rua Napoleão de Barros, 299

04024-002 São Paulo, SP

e-mail:sg-franco@uol.com.br 